\title{
Significant decreasing cloud cover during 1954-2005 due to more clear-sky days and less overcast days in China and its relation to aerosol
}

\author{
X. Xia \\ LAGEO, Institute of Atmospheric Physics, Chinese Academy of Sciences, Beijing, 100029, China \\ Correspondence to: X.Xia (xxa@mail.iap.ac.cn) \\ Received: 6 January 2012 - Revised: 16 February 2012 - Accepted: 19 March 2012 - Published: 26 March 2012
}

\begin{abstract}
An updated analysis of cloud cover during 19542005 in China was performed using homogeneous cloud cover data from 314 stations. Long-term changes in frequencies of different cloud cover categories and their contributions to long-term changes in cloud cover were assessed. Furthermore, aerosol effects on cloud cover trends were discussed based on comparison of cloud cover trends in polluted and mildly polluted regions. Frequencies of clear sky (cloud cover $<20 \%$ ) and overcast days (cloud cover $>80 \%$ ) were observed to increase by $\sim 2.2$ days and decrease by $\sim 3.3$ days per decade, respectively, which accounts for $\sim 80 \%$ of cloud cover reduction. Larger decreasing trends in cloud cover due to larger increase in clear sky frequency and larger decreases in overcast frequency were observed at stations with lower aerosol optical depth. There is no significant difference in trends regarding cloud cover, clear sky frequency, and overcast frequency between mountain and plain stations. These results are inconsistent with our expectation that larger decreasing trends in cloud cover should have been observed in regions with higher aerosol loading where more aerosols could lead to stronger obscuring effect on ground observation of cloud cover and stronger radiative effect as compared with the mildly polluted regions. Aerosol effect on decreasing cloud cover in China appear not to be supported by this analysis and therefore, further study on this issue is required.
\end{abstract}

Keywords. Atmospheric composition and structure (Aerosols and particles)

\section{Introduction}

Cloud cover is a key component of the global climate system, and complex feedbacks occur between cloud cover, temperature, and precipitation. Therefore, the detection of variations in cloud cover contributes to understanding climatic changes and the complex feedbacks associated with them (Warren et al., 2007). While observation data of cloud cover from satellites now spans 2-3 decades, conventional surface-based visual cloud observations have been ongoing worldwide since 1950 or earlier in some regions. Cloud cover datasets based on such visual observations have been compiled in several countries over recent decades, so they are more useful than satellite data in detecting long-term changes. Many prior studies have analyzed ground-based cloud cover data from particular countries or regions for variations in cloud cover, and some studies have been conducted regarding cloud-type variation. These studies have suggested total cloud cover has increased over Europe (Henderson-Sellers, 1986), Australia (Jones and Henderson-Sellers, 1992), Canada (Milewska, 2004), the United States (Sun and Groisman, 2004; Dai et al., 2006), the Former Soviet Union (Sun and Groisman, 2000), and the northern Indian Ocean (Norris, 2001). In contrast, a decreasing trend in the annual-mean total cloud cover has been revealed over much of China during 1954-1996 (Kaiser, 2000) and 1954-2005 (Xia, 2010a). Decline in total cloud cover over China and its neighbors during 1971-1996 appears to be largely attributable to high and middle-layer clouds (Warren et al., 2007). It was shown that a decrease in cirrus clouds was a major contributor to the negative trend, primarily in the north in winter and in the south in summer (Warren et al., 2007). 
It has been widely suggested that aerosol optical depth (AOD) has increased with rapid economic development and population growth in China. AOD was observed to increase from 0.38 in 1960 to 0.47 in 1990 (Luo et al., 2001; Qiu and Yang, 2000). This trend has been confirmed by a significant decrease in good visibility $(>20 \mathrm{~km})$ in eastern China (Che et al., 2007; Liang and Xia, 2005). The AOD increase in China might influence cloud cover through the following mechanisms: First, more aerosols in the atmosphere can obscure ground observations of very thin high and middle-level clouds, thereby leading to observations of a smaller total apparent cloud cover (Warren et al., 2007). Second, clouds may be inhibited via the aerosol radiative effect (Koren et al., 2008). More aerosols with stronger absorption can lead to greater stability of the atmosphere, less relative humidity and surface evapotranspiration, thereby resulting in to less cloud coverage. The aerosol absorption of solar energy increases steadily with AOD and decreases with cloud cover. Therefore, cloud fields with a low cloud fraction will be strongly inhibited by aerosol absorption if AOD exceeds 0.25 (Koren et al., 2008). The small coverage of thin clouds is therefore expected to become smaller and thinner because mean AOD in mideastern China is 0.5 and increasing to 0.7 around major cities that reduced daily mean surface solar radiation by 30 $40 \mathrm{~W} \mathrm{~m}^{-2}$ (Li et al., 2007). Finally, aerosol is also likely to invigorate clouds via its microphysical effect: more aerosols $\rightarrow$ more cloud condensation nuclei $\rightarrow$ more cloud drops $\rightarrow$ suppressed coalescence $\rightarrow$ less rain $\rightarrow$ larger cloud fraction. This microphysical effect is expected to overwhelm the radiative effect in clear regions if the sky is covered by large cloud fields. This suggests that the overcast mode might last longer with thicker clouds.

Evidence from this study shows that the decreasing cloud cover in China is primarily attributable to increasing clearsky days and decreasing overcast days on a decadal time scale. More importantly, aerosol effects on cloud cover was investigated by comparing cloud cover trends derived at stations in polluted and relatively clean areas.

This study differs from previous studies in several ways. First, a homogeneous test of cloud cover data was performed, and only homogeneous time series were used in the analysis. Second, an effective statistical method was applied to study quantitative contributions of graded cloudiness occurrence to the overall trend. Third, potential effects of aerosol on cloud cover were analyzed. The results of the analysis, investigations, and discussion are presented in the following sections.

\section{Database and methodology}

\subsection{Total cloud cover data}

Total cloud cover (TCC) observations are considered according to the amount of sky estimated to be covered by all cloud types. The climatic variables, including cloud cover, are ob- served at 1-h intervals at national climate observation stations (143 stations), but observations are made at 3-h intervals at national basic weather observation stations (530 stations). Daily cloud cover data are derived from observations at 6-h intervals: 02:00, 08:00, 14:00, and 20:00 Beijing Time of cloud cover (0-100\% of sky), which are available from the climate data center, China Meteorological Administration (CMA). Quality control of daily and nighttime observations was performed separately; however, metadata pertaining to an illuminence requirement for nighttime observations is not completely clear (http://cdc.cma.gov.cn/). It was suggested that visual estimates of total cloud cover made by human observers were not affected by stations moves, as no obvious stepwise changes were observed in total cloud cover for any of the stations (Kaiser, 2000). However, homogeneous tests using the latest version of RHtest V3 package (Wang, 2008a, b) show that $\sim 50 \%$ of total cloud cover during 1954-2005 proved inhomogeneous (Xia, 2010a). To minimize effects of inhomogeneity of data on the analysis, only homogeneous time series of total cloud cover at 314 stations during 1954-2005 were used in this study.

\subsection{Cloud cover data analysis}

To quantitatively estimate how much TCC variability is attributable to occurrence of different sky conditions, five TCC categories were defined: $0-20 \%, 20-40 \%, 40-60 \%, 60-$ $80 \%$, and $80-100 \%$. Days with TCC $<20 \%$ or $>80 \%$ were defined as clear-sky days and overcast days, respectively. More than 20 daily observations of TCC were used to calculate monthly average; at least 2 monthly values were required to calculate seasonal averages. Seasons were defined as winter (December, January, and February), spring (March, April, and May), summer (June, July, and August), and autumn (September, October, and November). The annual value was the average of four seasonal values.

TCC trends originate from changes in frequency of TCC categories. An increase of days with TCCs less than the average or a decrease of days with TCCs larger than the average would indicate a decline in cloud cover. The yearly TCC sum was equal to the averaged $\overline{\mathrm{TCC}_{\mathrm{y}}}$ multiplied by total number of daily TCC observations.

$\sum_{d=1}^{N_{\mathrm{y}}} \mathrm{TCC}_{\mathrm{y}, \mathrm{d}}=N_{\mathrm{y}} \times \overline{\mathrm{TCC}_{\mathrm{y}}}$

where $N_{\mathrm{y}}$ is total number of daily TCC observation each year. Graded daily TCCs was related to overall averaged TCC as follows.

$$
\begin{aligned}
\sum_{d=1}^{N_{\mathrm{y}}} \mathrm{TCC}_{\mathrm{y}, \mathrm{d}} & =N_{\mathrm{y}} \times \overline{\mathrm{TCC}_{\mathrm{y}}}=\sum_{g=1}^{5} \sum_{d_{\mathrm{g}}=1}^{N_{\mathrm{y}, \mathrm{g}}} \mathrm{TCC}_{\mathrm{y}, \mathrm{d}_{\mathrm{g}}} \\
& =\sum_{g=1}^{5} N_{\mathrm{y}, \mathrm{g}} \times \overline{\mathrm{TCC}_{\mathrm{y}, \mathrm{g}}}
\end{aligned}
$$


where $\overline{\mathrm{TCC}_{\mathrm{y}, \mathrm{d}_{\mathrm{g}}}}$ is daily graded TCC and $\overline{\mathrm{TCC}_{\mathrm{y}, \mathrm{g}}}$ is the yearly averaged graded TCC and $N_{\mathrm{y}, \mathrm{g}}$ is graded total number of daily observations. The Eq. (2) can be divided by $N_{\mathrm{y}}$ to derive the following equation.

$\overline{\mathrm{TCC}_{\mathrm{y}}}=\sum_{g=1}^{5} N_{\mathrm{y}, \mathrm{g}} / N_{\mathrm{y}} \times \overline{\mathrm{TCC}_{\mathrm{y}, \mathrm{g}}}=\sum_{g=1}^{5} f_{\mathrm{y}, \mathrm{g}} \times \overline{\mathrm{TCC}_{\mathrm{y}, \mathrm{g}}}$

where $f_{\mathrm{y}, \mathrm{g}}$ is yearly occurrence frequency of graded TCC.

The first derivative of Euqation 3 with regard to time was calculated and the following equation was finally obtained:

$\omega_{\mathrm{TCC}}=\sum_{g=1}^{5}\left(\omega_{\mathrm{TCC}_{\mathrm{g}}} \times \overline{f_{\mathrm{g}}}+\omega_{f_{\mathrm{g}}} \times \overline{\mathrm{TCC}_{\mathrm{g}}}\right)$

where $\omega_{\mathrm{TCC}}$ and $\omega_{\mathrm{TCC}}$ represent linear trends calculated using least squares linear fitting of the total TCC and TCC for the grade $g . \omega_{f_{\mathrm{g}}}$ represents linear trend of frequency for the grade $g . \overline{\mathrm{TCC}_{\mathrm{g}}}$ and $\overline{f_{\mathrm{g}}}$ represent multiyear average TCC and frequency for TCC grade $g$. Given the fact that $\omega_{\mathrm{TCC}}$ were negligible due to a very narrow TCC range for each cloud cover category, the TCC trend could be calculated as follows.

$\omega_{\mathrm{TCC}}=\sum_{g=1}^{5}\left(\omega_{f_{\mathrm{g}}} \times \overline{\mathrm{TCC}_{\mathrm{g}}}\right)$

Note that the sum of $\omega_{f_{\mathrm{g}}}$ is zero, therefore, Eq. (5) was reorganized into Eq. (6) based on following considerations: First, TCC trend is primarily attributable to changes in frequency of those TCC categories with $\overline{\mathrm{TCC}_{\mathrm{g}}}$ far from $\overline{\mathrm{TCC}}$. Second, cloud cover should decrease if $f_{\mathrm{g}}$ of those TCC categories with $\overline{\mathrm{TCC}_{\mathrm{g}}}<\overline{\mathrm{TCC}}$ increases and vice versa:

$\omega_{\mathrm{TCC}}=\sum_{g=1}^{5} \omega_{f_{\mathrm{g}}} \times\left(\overline{\mathrm{TCC}_{\mathrm{g}}}-\overline{\mathrm{TCC}}\right)$

Therefore, based on Eq. (6), we can quantitatively estimate how much contribution to overall cloud cover trend is made by changes in each cloud category frequency.

\subsection{Analysis of relationship between AOD and cloud cover trend}

Aerosol may influence apparent cloud cover via three mechanisms (i.e. aerosol obscuring ground observation of cloud cover, aerosol radiative effect, and aerosol microphysical effect). The first one is an artifact, while the next two are plausible physical mechanisms. The first two mechanisms may produce a negative effect, i.e. more aerosols, smaller cloud covers; however, the third mechanism leads to a positive effect, i.e. more aerosols, larger cloud covers. Note that the third mechanism decreases and aerosol radiative effect increases as AOD increases (Koren et al., 2008). It has been suggested that decreasing cloud cover observed in China is associated with increasing aerosol obscuring effect

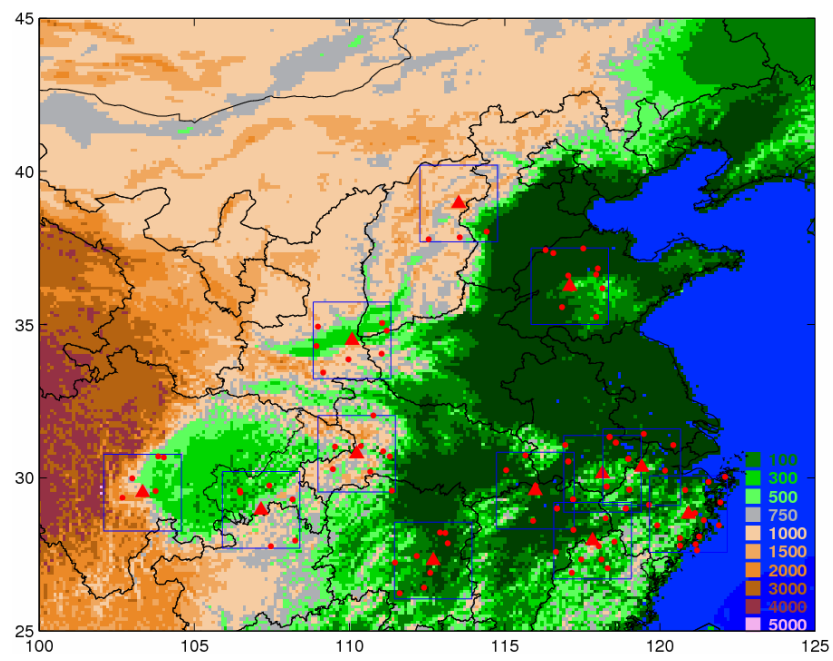

Fig. 1. Twelve mountain stations (solid triangles) and their corresponding plain stations (solid dots). The background represents the altitude in meters.

on ground observation of cloud cover (Warren et al., 2007) and aerosol radiative effects (Wild, 2012). If this is true, we expect larger aerosol negative effects on cloud cover at stations with larger AODs compared with that at stations with lower AODs, which means larger decreasing trends of cloud cover should be observed at stations with larger AODs, and vice versa. This expection was tested in the following two ways: first, linear analysis of relationship between cloud cover trend and AOD was performed. The moderate resolution imaging spectroradiometer (MODIS) collection 5 Level2 AOD data (10-km resolution) from March 2000 to February 2010 were used to calculate seasonal and annual average AOD. AOD at each station was derived from the nearest MODIS pixel. Second, cloud cover trends at mountain stations were compared with those at surrounding plain stations. The assumption behind this analysis is that AOD at mountain stations is lower than that at plain stations. Plain stations located within a grid square $\left(2.5^{\circ} \times 2.5^{\circ}\right)$ with mountain stations as the center were used for comparison. Figure 1 presents the distribution of 12 mountain stations and their surrounding plain stations.

\section{Long-term trend of cloud cover}

Figure 2 presents station trends of annual and seasonal cloud cover on a decadal time scale. Significant decrease of cloud cover is evident over much of China. Some of the trends could be artificial due to subjective nature of cloud observations. Nonetheless, the degree of confidence in trends of cloud coverage is improved by their spatial homogeneity. These results are in agreement with the results obtained by Kaiser (2000) using data from 1951-1996, although our trends are generally larger. The largest decline in cloud cover 

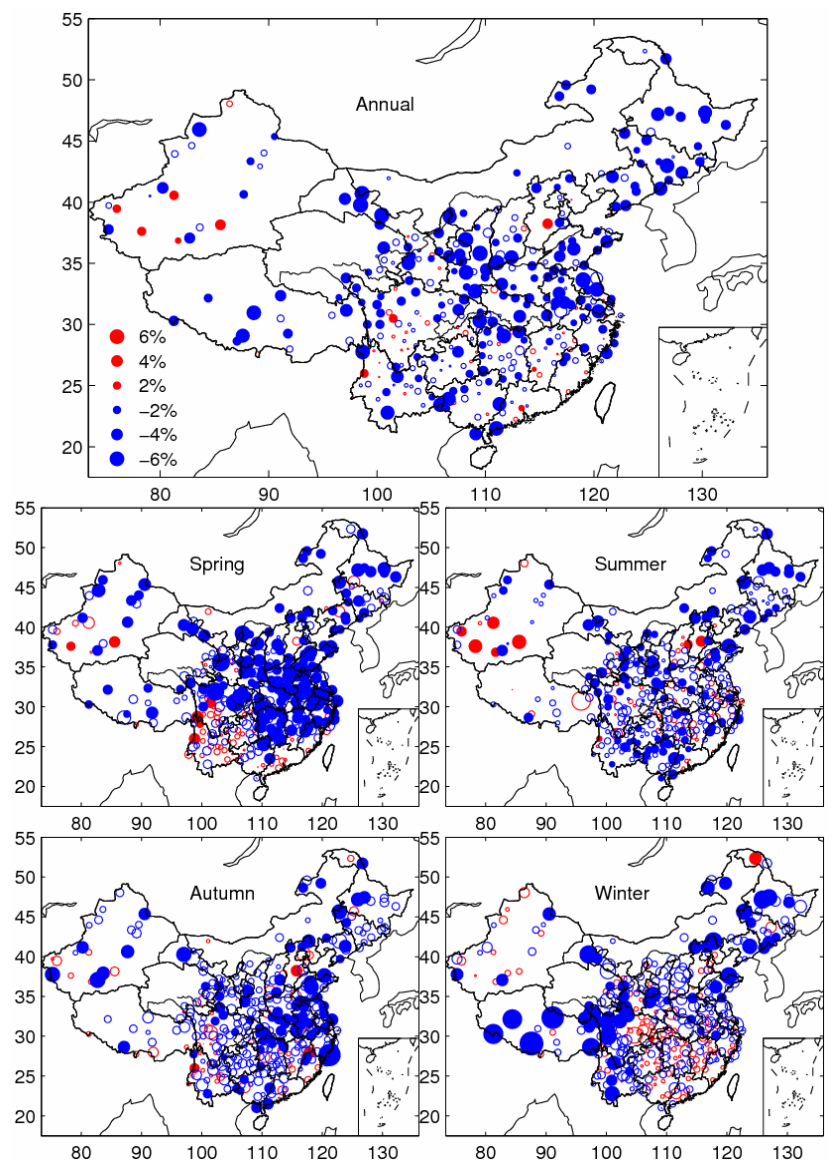

Fig. 2. Annual and seasonal mean total cloud cover trend (\% per decade) at each station during 1954-2005. Blue and red circles represent decreasing and increasing trends, respectively with area proportional to trend magnitude and referenced in legend. Solid circles indicate trends different from zero at the $95 \%$ significance level.

appears in northern China, where cloud cover decreased significantly by $>10 \%$ per decade. Nearly all cloud covers since 1996 are below the normal during 1971-2000; therefore our study revealed larger trends than those obtained using data during 1951-1996. The national average TCC trend was produced by fist taking an unweighted average of station trends for each 2.5 degree by 2.5 degree grid box over China. Grid box trends were then weighted by the area lying within China. The results showed that national annual TCC declined by $1.6 \%$ per decade and the seasonal trends were $1.8 \%, 1.0 \%, 1.6 \%$, and $1.4 \%$ per decade for spring, summer, autumn, and winter, respectively.

Station trends of annual and seasonal occurrences of the five cloud categories were calculated, and the results for clear sky and overcast sky are presented in Figs. 3 and 4. Annual frequency of clear sky shows an upward trend, and a downward trend is revealed for annual frequency of overcast sky at $\sim 85 \%$ of stations. Greater frequency of clear sky is
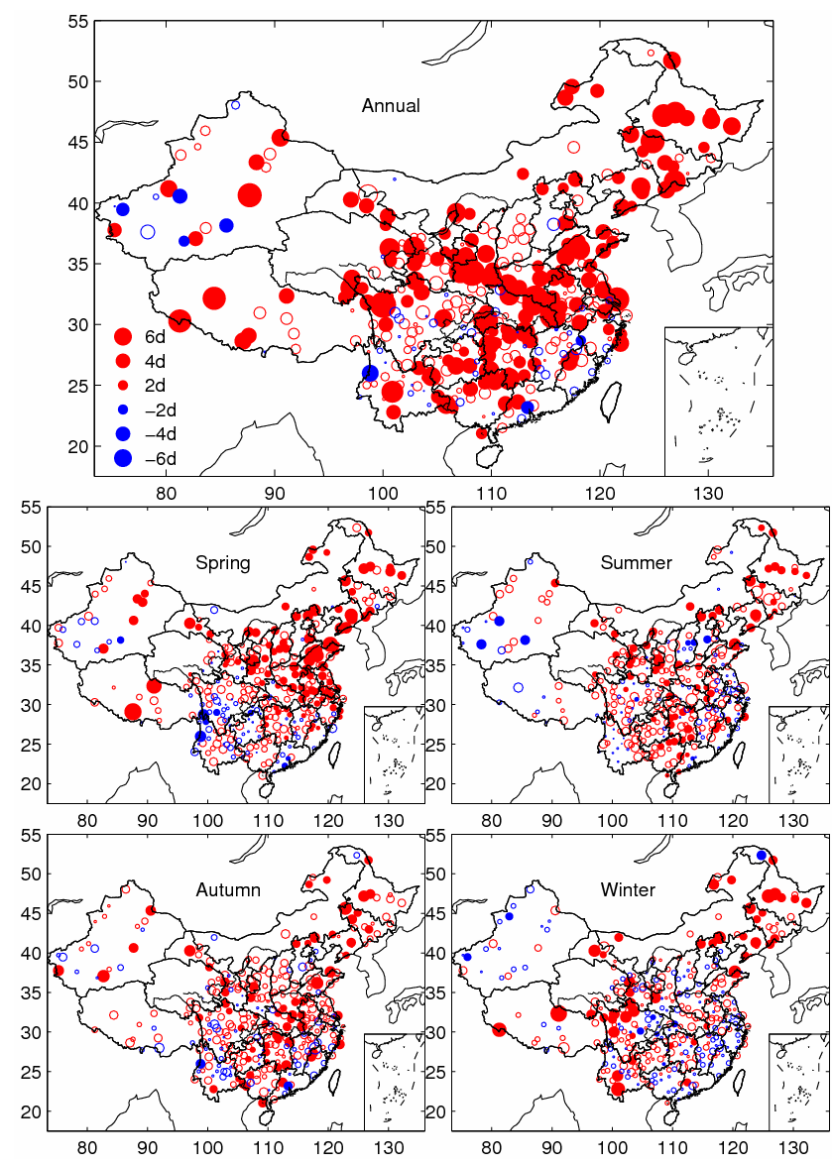

Fig. 3. Annual and seasonal trends (days per decade) in clear sky frequency (TCC $<20 \%$ ) during 1954-2005. Blue and red circles represent decreasing and increasing trends, respectively with area proportional to trend magnitude and referenced in legend. Solid circles indicate trends different from zero at the $95 \%$ significance level.

Table 1. Long-term trend of frequency of each TCC category $\left(\omega f_{\mathrm{g}}\right.$ of Eq. (6), unit: days per decade).

\begin{tabular}{crrrrr}
\hline Cloudiness & Spring & Summer & Autumn & Winter & Annual \\
\hline $0-2$ & 0.55 & 0.38 & 0.58 & 0.43 & 2.21 \\
$2-4$ & 0.35 & 0.28 & 0.21 & 0.05 & 0.97 \\
$4-6$ & 0.22 & 0.26 & 0.06 & -0.04 & 0.51 \\
$6-8$ & -0.06 & 0.04 & -0.13 & -0.18 & -0.40 \\
$8-10$ & -1.07 & -0.95 & -0.71 & -0.26 & -3.32 \\
\hline
\end{tabular}

consistent with the results of Qian et al. (2006). For the national averages, annual frequency of clear sky and overcast sky changed by +2.2 days per decade and -3.3 days per decade, respectively (Table 1). The trend for the remaining cloud categories was smaller, and there was a larger spatial variation compared with that of clear sky and overcast sky (not shown). 


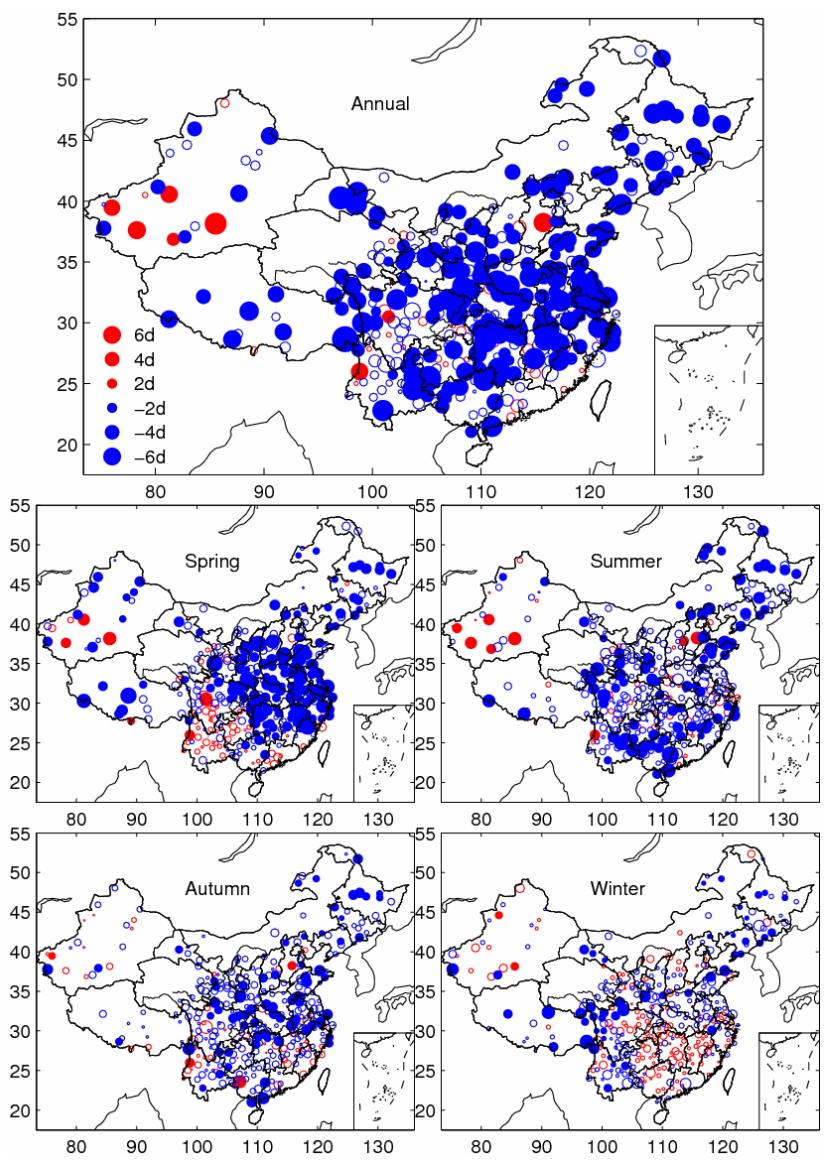

Fig. 4. The same as Fig. 3 but for overcast frequency (TCC $>80 \%)$.

Further analysis here reveals quantitative contribution by changes in clear-sky days and overcast days to the overall trend that is calculated as follows: $\left[\omega_{f_{\text {clear-sky }}} \times\left(\overline{\mathrm{TCC}_{\text {clear}- \text { sky }}}-\overline{\mathrm{TCC}}\right)\right] / \omega_{\mathrm{TCC}} \times 100,\left[\omega_{f_{\text {overcast }}} \times\right.$ $\left.\left(\overline{\mathrm{TCC}_{\text {overcast }}}-\overline{\mathrm{TCC}}\right)\right] / \omega_{\mathrm{TCC}} \times 100$, respectively. The results are presented in Figs. 5 and 6 . It is clearly shown that a combination of increase in clear-sky days and decrease in overcast days over much of China accounts for most of the decline in TCC. The sum of contributions by $\omega_{f_{\text {clear-sky }}}$ and $\omega_{f_{\text {overcast }}}$ accounts for $\sim 80 \%$ of $\omega_{\text {TCC }}$ for the national average (Table 2).

It has been suggested that cloud may be invigorated via the aerosol microphysical effect when the sky is covered by large cloud fields. Therefore, the overcast mode would last longer with thicker clouds due to the aerosol microphysical effect, which appears to be not in agreement with the observed significant decline in overcast days. The fact that more clear skies have been observed in China appears to be consistent with aerosol radiative effect on cloud cover because one would expect the small coverage of thin clouds to become smaller and thinner due to higher AOD in China. However, this speculation is not supported by the analysis below.

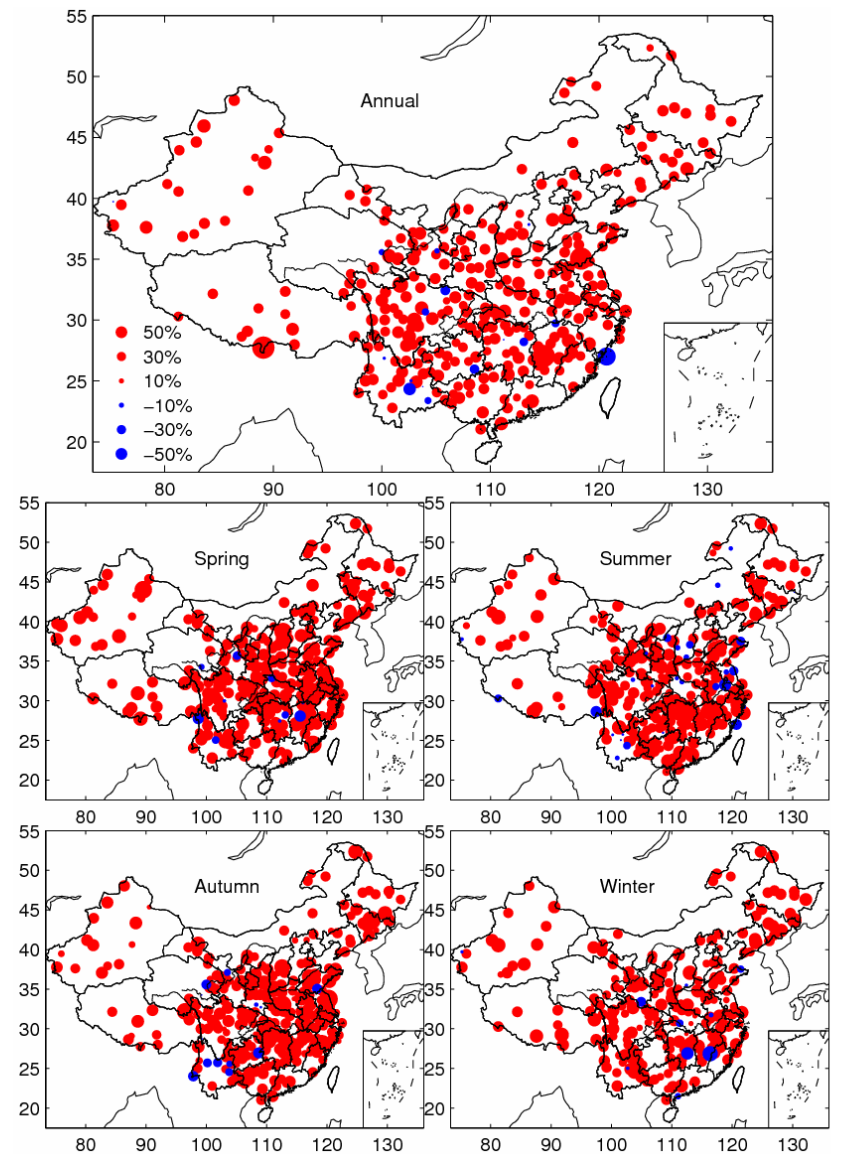

Fig. 5. Contribution by changes in clear sky frequency to total cloud cover trend which is calculated using Eq. (6), i.e. $\left[\omega f_{\text {clear-sky }} \times\right.$ $\left.\left(\overline{\mathrm{TCC}_{\text {clear}- \text { sky }}}-\overline{\mathrm{TCC}}\right)\right] / \omega_{\mathrm{TCC}} \times 100$.

Table 2. Contribution of changes in frequency of each TCC category to the overall trend in TCC $(\%)$ (i.e. $\left[\omega_{f_{\mathrm{g}}} \times\left(\overline{\mathrm{TCC}_{\mathrm{g}}}-\right.\right.$ $\left.\overline{\mathrm{TCC}})] / \omega_{\mathrm{TCC}} \times 100\right)$.

\begin{tabular}{crrrrr}
\hline Cloudiness & Spring & Summer & Autumn & Winter & Annual \\
\hline $0-2$ & 42.5 & 36.1 & 33.8 & 43.3 & 43.0 \\
$2-4$ & 10.9 & 14.4 & 17.9 & 8.6 & 6.0 \\
$4-6$ & 2.8 & 6.6 & 9.2 & 2.2 & 2.7 \\
$6-8$ & 3.2 & 4.5 & 2.8 & 4.2 & 6.6 \\
$8-10$ & 40.5 & 38.3 & 36.2 & 41.7 & 41.6 \\
\hline
\end{tabular}

\section{Relationship between AOD and cloud cover trend}

Spatial distribution of AOD and regionalization of stations are shown in Fig. 7. Because there is a large spatial variation of cloud cover trend (Fig. 2), linear analysis between AOD and cloud cover trend was performed at a regional scale. Regionalization of stations was achieved using a factor analysis with varimax rotation, which is able to classify stations with similar cloud cover variability (Xia, 2010a). Figure 8 


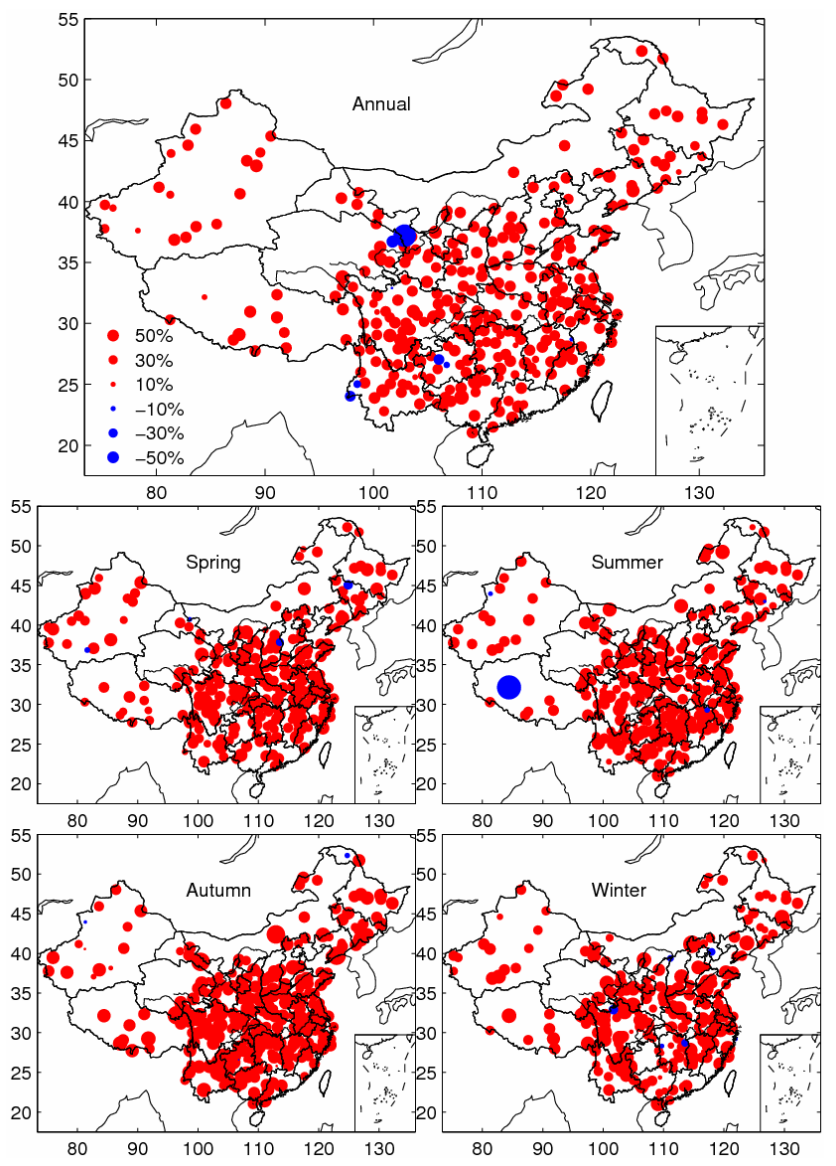

Fig. 6. The same as Fig. 5 but for the overcast frequency, i.e. $\left[\omega_{f_{\text {overcast }}} \times\left(\overline{\mathrm{TCC}_{\text {overcast }}}-\overline{\mathrm{TCC}}\right)\right] / \omega_{\mathrm{TCC}} \times 100$.

shows the scatter plot between seasonal mean station AODs and cloud cover trends in four regions. An outstanding features is that there is a positive relation in 13 of 16 cases and the relation is significant at the $95 \%$ confidence level in 9 out of 13 cases. The fact that relatively larger decreasing trends were generally observed at stations with lower AODs is inconsitent with the speculation about aerosol effects on cloud cover in China mentioned above.

Figures 9 and 10 present the scatter plot between AOD and trends of clear sky and overcast sky frequencies. AOD shows a negative correlation with trend of clear days in 14 of 16 cases; however, a positive correlation was observed between AOD and trend of overcast days in 13 of 16 cases. These analyses also do not support the speculation mentioned in the previous section.

The decadal time series of annual deviation of cloud cover at mountain stations and their corresponding plain stations is shown in Fig. 11. Cloud cover trend and correlation coefficient between time series of mountain and plain stations are shown in Table 3. Note that the trends at plain stations were derived from the average of time series of all plain stations associated with one mountain station. The bold values that

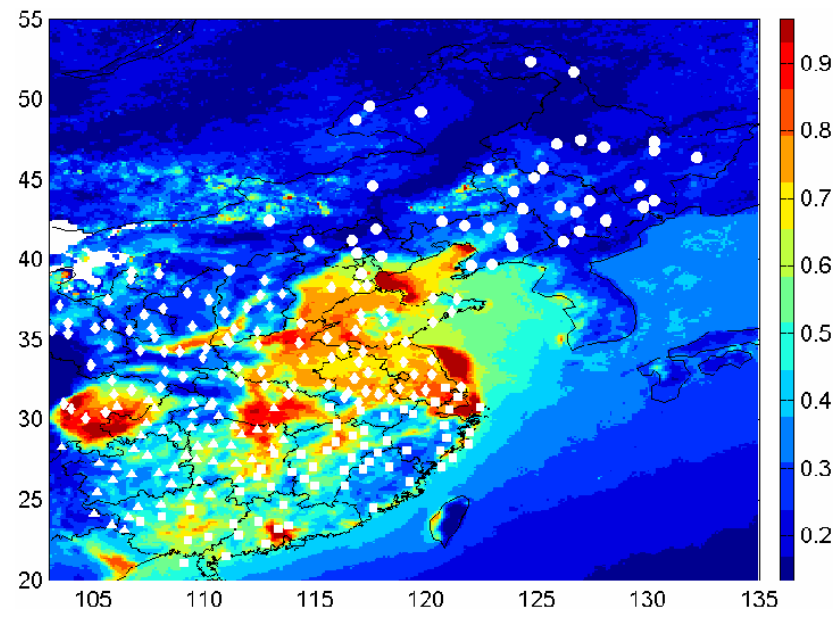

Fig. 7. Spatial distribution of aerosol optical depth at $550 \mathrm{~nm}$ and regionalization of stations.

represent the trends are significant at the $95 \%$ confidence level. More than $75 \%$ of cloud cover variation at plain stations can be explained by that at mountain stations except at Mt. Wutai, which suggests a good agreement in the interannual variation of cloud cover between plain and mountain stations due to the short distance between them. Variation of cloud cover at Mt. Wutai since 1998 deviates from that at plain stations because the station was moved from the top to the foot of the Wutaishan Mountain. Therefore, trend and correlation coefficients listed in Table 3 were derived using data during 1954-1995 at Mt. Wutai. The decreasing trend at mountain stations was smaller than that at plain stations in 9 of 12 cases, which led to a smaller average cloud cover trend at mountain stations ( -0.04 per decade) as compared with that at plain stations $(-0.06$ per decade). However, the difference is not significant at the $95 \%$ confidence level using Student's $t$ test. Similar analyses were also performed for overcast sky and clear sky frequencies (see Table 3). The average overcast frequency at mountain stations was observed to decrease by 0.17 days per decade. This decrease was smaller than that at plain station ( -0.21 days per decade). Furthermore, clear sky frequency at mountain stations was observed to increase by 0.05 days per decade. This increase was also smaller than that at plain stations ( 0.12 days per decade). These analyses appear to be consistent with the speculation regarding the aerosol radiative effects on cloud cover; however, this suggestion is refuted by the fact that the differences in trends of overcast sky and clear sky frequencies between mountain and plain stations are not significant at the $95 \%$ confidence.

\section{Discussion}

Total cloud cover observations were used in the analysis. We expected to find larger aerosol effects on low-level cloud 

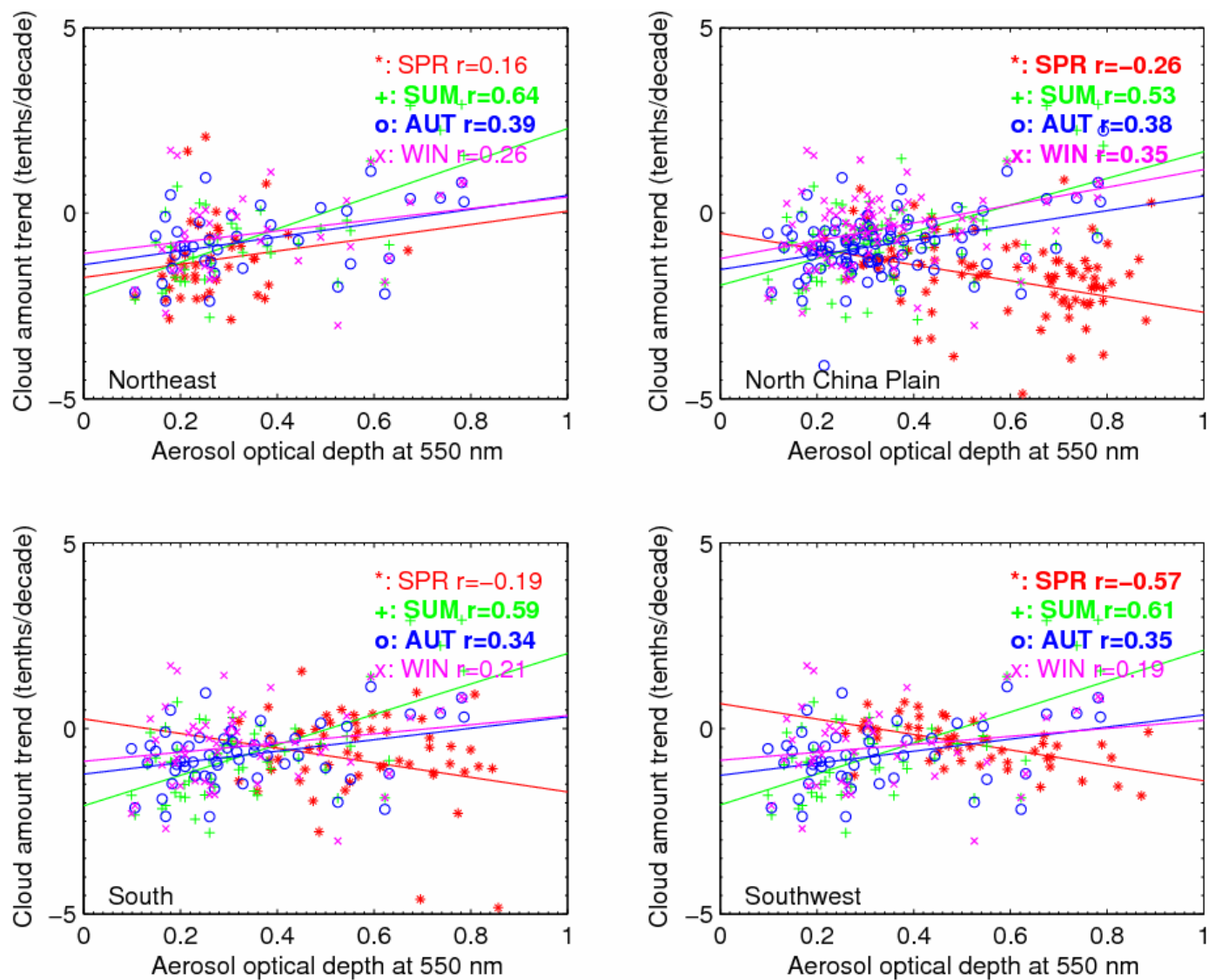

Fig. 8. Scatter plot between aerosol optical depth at $550 \mathrm{~nm}$ and cloud cover trend by season in four regions.

Table 3. Comparison of trend in TCC, overcast sky, and clear sky frequencies between mountain and plain stations. M and P represent mountain and plain. R represents the correlation coefficient between time series of TCC in mountain and plain stations.

\begin{tabular}{|c|c|c|c|c|c|c|c|c|c|}
\hline \multirow{2}{*}{ Station } & \multicolumn{3}{|c|}{ Cloud cover } & \multicolumn{3}{|c|}{ Overcast sky frequency } & \multicolumn{3}{|c|}{ Clear sky frequency } \\
\hline & M & $\mathrm{P}$ & $\mathrm{R}$ & M & $\mathrm{P}$ & $\mathrm{R}$ & M & $\mathrm{P}$ & $\mathrm{R}$ \\
\hline Huang & -0.14 & -0.07 & 0.89 & -0.58 & -0.26 & 0.86 & 0.28 & 0.11 & 0.67 \\
\hline Luocongpo & -0.04 & -0.07 & 0.93 & -0.08 & -0.26 & 0.93 & 0.09 & 0.12 & 0.79 \\
\hline Heng & -0.06 & -0.05 & 0.92 & -0.31 & -0.20 & 0.84 & 0.04 & 0.12 & 0.80 \\
\hline $\mathrm{Lu}$ & -0.05 & -0.06 & 0.94 & -0.34 & -0.25 & 0.92 & -0.02 & 0.14 & 0.76 \\
\hline Tai & -0.07 & -0.16 & 0.86 & -0.17 & -0.44 & 0.79 & 0.12 & 0.43 & 0.79 \\
\hline Wutai & -0.04 & -0.07 & 0.73 & -0.24 & -0.26 & 0.69 & -0.04 & 0.10 & 0.57 \\
\hline Hua & -0.10 & -0.08 & 0.89 & -0.36 & -0.23 & 0.83 & 0.25 & 0.17 & 0.88 \\
\hline Ermei & -0.02 & -0.03 & 0.75 & -0.06 & -0.19 & 0.75 & 0.05 & 0.03 & 0.43 \\
\hline Tianmu & -0.01 & -0.05 & 0.89 & -0.10 & -0.18 & 0.90 & 0.07 & 0.10 & 0.72 \\
\hline Guacang & 0.01 & -0.01 & 0.93 & 0.17 & -0.05 & 0.86 & -0.03 & 0.00 & 0.88 \\
\hline Jinfo & 0.00 & -0.01 & 0.91 & -0.01 & -0.08 & 0.89 & -0.02 & 0.02 & 0.64 \\
\hline Qixian & 0.04 & -0.02 & 0.91 & 0.09 & -0.08 & 0.88 & -0.16 & 0.08 & 0.68 \\
\hline Average & -0.04 & -0.06 & 0.88 & -0.17 & -0.21 & 0.84 & 0.05 & 0.12 & 0.72 \\
\hline
\end{tabular}

covers; therefore, further study to determine whether the observed changes come from lower or upper levels is required, as well as investigation of the relationship between these changes and AOD. However, low-level cloud cover ob- servations proved to be inhomogeneous in most cases (Xia, 2010a), which prevent similar analysis using low-level cloud cover data. Meteorology is a key factor determining cloud cover. Changes in global atmospheric circulation should 

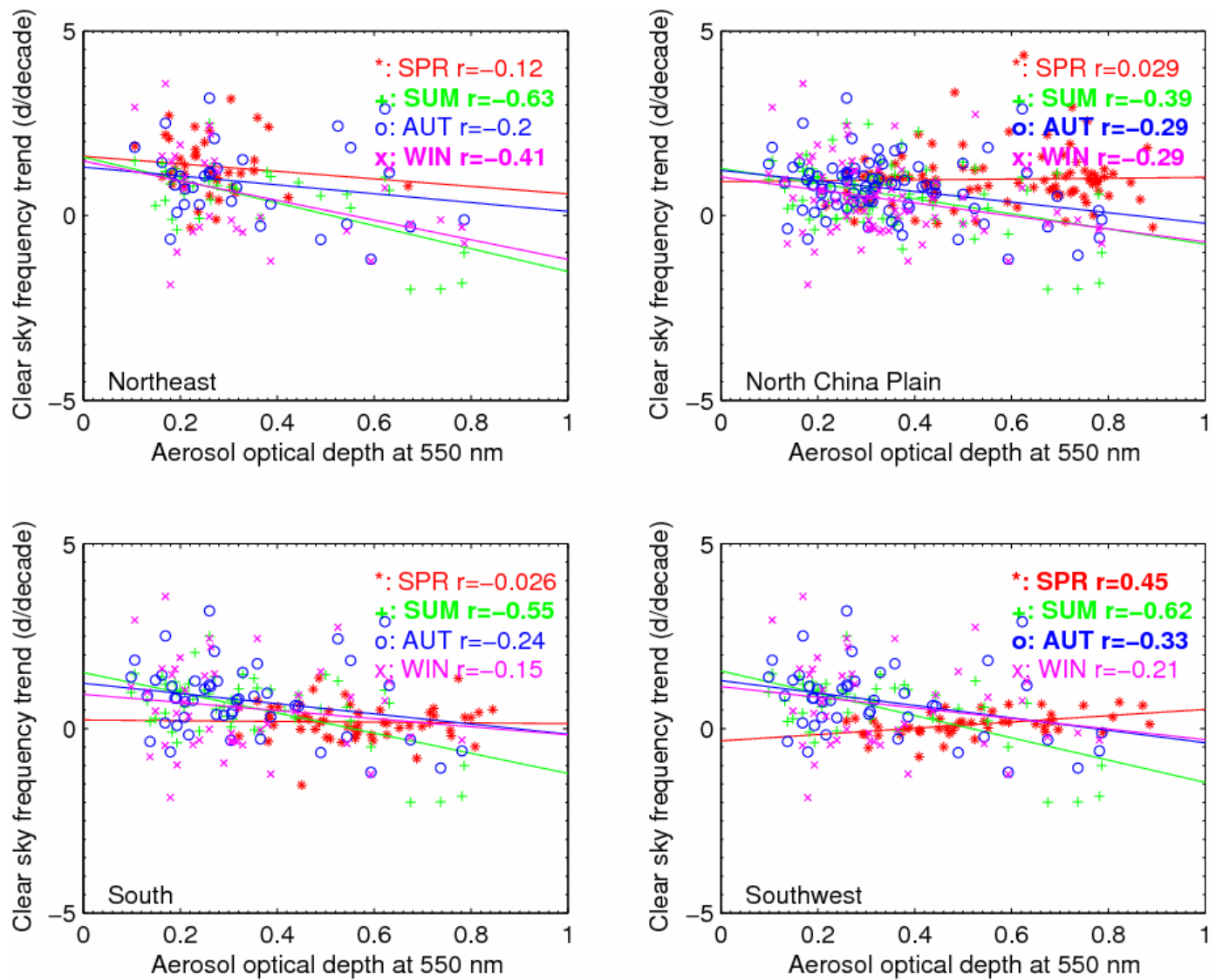

Fig. 9. Scatter plot between aerosol optical depth at $550 \mathrm{~nm}$ and clear sky frequency trend by season in four regions.

have played an important role in variability of cloud cover. A significant weakening trend in the interdecadal variations of the East Asian monsoon system from the late 1970s has been reported; this trend has led to an exceptionally deficient moisture supply for cloud formation in North China (Wang, 2001; Ding et al., 2008; Huang et al., 2008). Research on the effect of decadal variation of East Asian monsoon on cloud cover is required.

A few studies have shown a significant decline in surface solar radiatin during 1961-1990 over much of China, however, in the 1990s, the downward trend leveled off or even changed sign (Xia, 2010b, and references therein). It appears that decadal variation of TCC cannot explain dimming in China. Increased clear sky frequency and decreased overcast frequency in China should have resulted in brightening, however, it has been completely offset by significant decrease of atmospheric transmittance under clear sky and cloudy condition, which resulted in dimming in China (Xia, 2010b). Decrease of clear-sky surface solar radiation were probably related to increased aerosol extinction (Che et al., 2007; Qian et al., 2006; Wild, 2009). A decrease of the cloud transmissivity may be associated with an increased frequency of multilevel cloudiness, changing cloud types, or by indirect aerosol effects on clouds which needs further study.

\section{Summary}

A homogeneous cloud cover dataset in China was used to study long-term changes in cloud cover and frequencies of cloud cover categories. A simple yet effective statistical method was applied to study quantitative contributions of graded cloud cover frequency to the overall trend in cloud cover. The relationship between AOD and cloud cover trend was analyzed to discuss aerosol effects on decadal trend of cloud cover. Major conclusions follow.

Significant decline in cloud cover with trend of $-1.6 \%$ per decade during 1954-2005 was derived. Occurrences of clear sky (cloud cover $<20 \%$ ) and overcast days (>80\%) were observed to increase and decline by $\sim 2.2$ days per decade and $\sim 3.3$ days per decade, respectively. Approximately $80 \%$ of overall trend of cloud cover is attributable to an increase in clear-sky days and a decline in overcast days.

Larger decreasing cloud-amount trends have been observed due to larger increasing clear sky frequency and larger decreasing overcast frequency at stations with lower AOD. There is not significant difference among trends of cloud cover, clear sky frequency, and overcast sky frequency between mountain and plain stations. These analyses do not support the speculation that the decreasing trend of cloud 

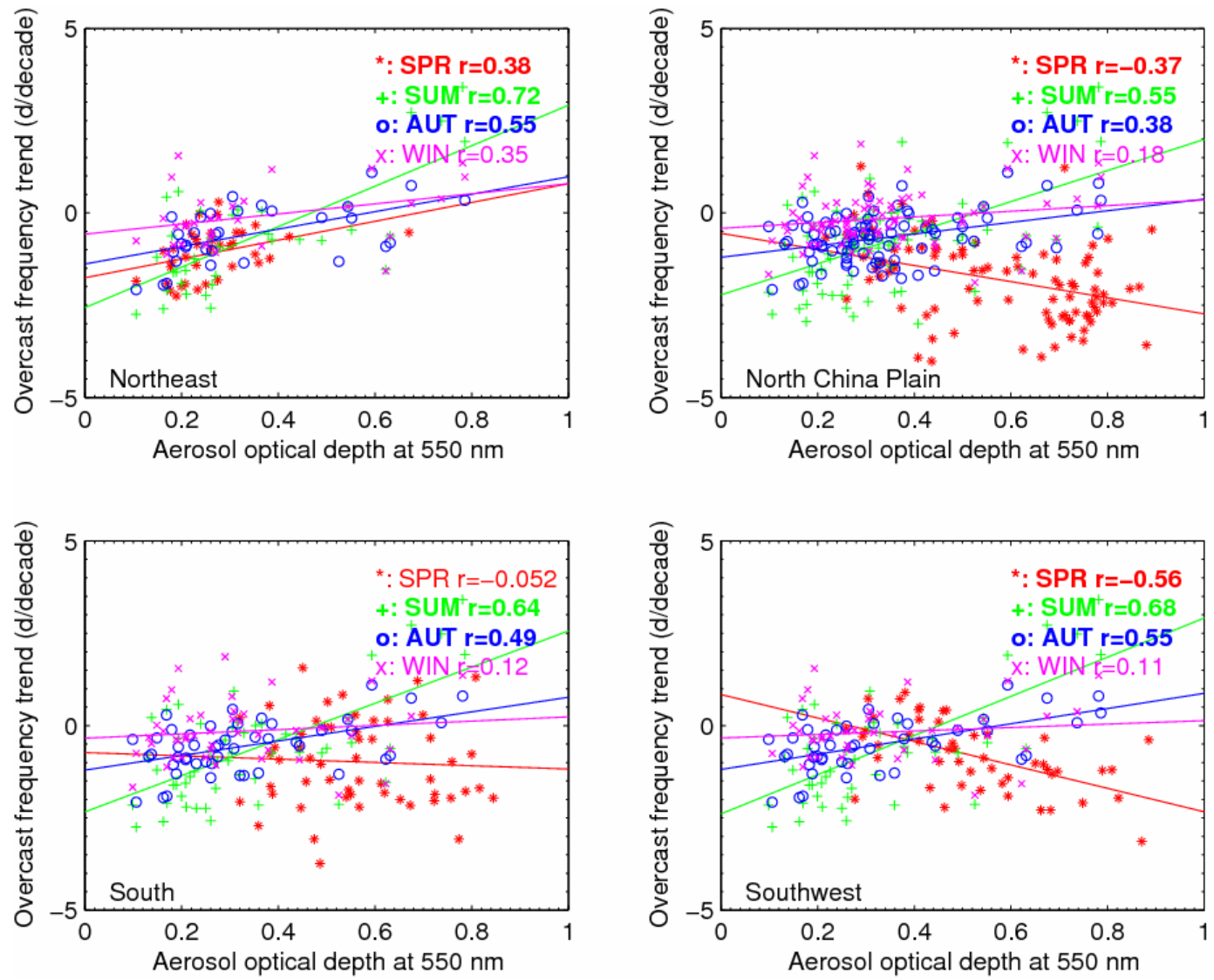

Fig. 10. Scatter plot between aerosol optical depth at $550 \mathrm{~nm}$ and overcast frequency trend by season in four regions.

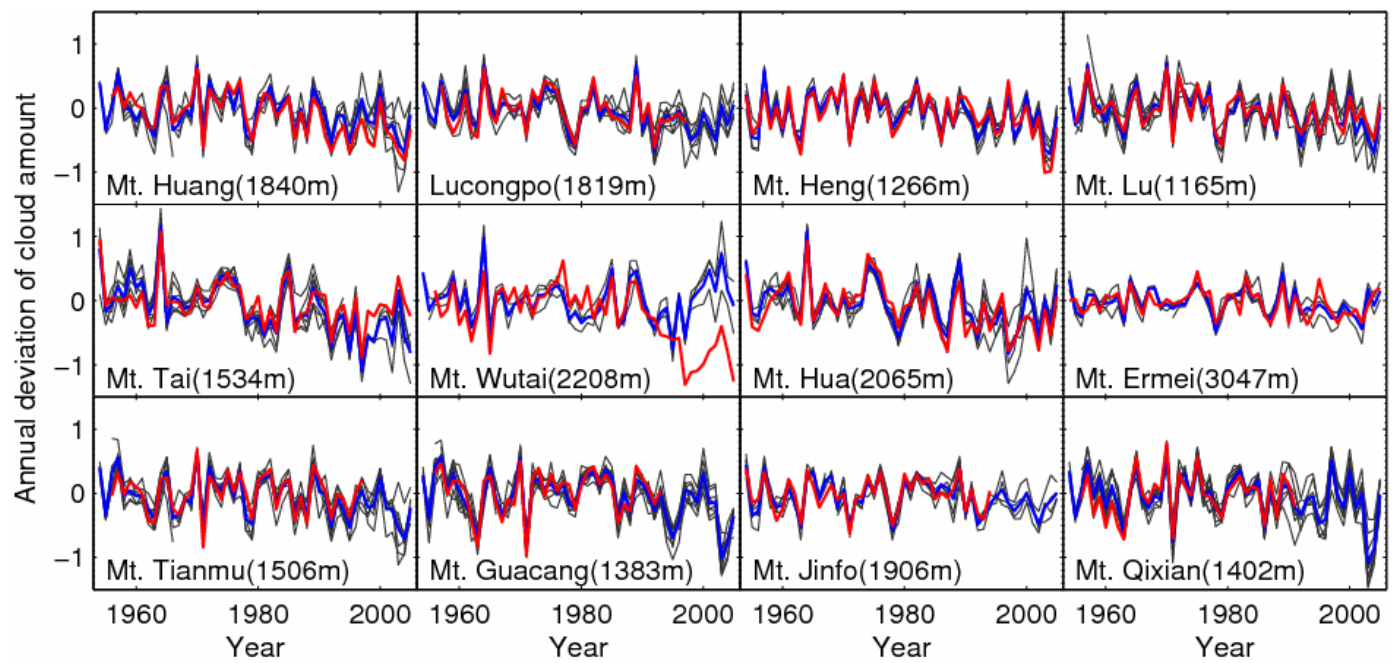

Fig. 11. Time series of cloud cover at mountain (red) and plain stations (blue). The grey lines represent the time series at individual plain station.

cover in regions with higher AOD should be larger than that in mildly polluted regions due to stronger aerosol obscuring effect on ground observation of cloud cover and stronger radiative effect in polluted regions. This suggests that causes for significant decreasing trend in cloud cover in China require further study. 
Acknowledgements. The cloud data were provided by the Climate Data Center, Chinese Meteorological Administration. This research was supported by the National Basis Research Program of China (2009CB723904), the Knowledge Innovation Program of the Chinese Academy of Sciences (KZCX2-YW-QN201) and the National Natural Science Foundation of China (41175031). Discussion with Jianchun Bian about the statistical analysis is appreciated. I greatly appreciate Ryan Eastman and an anonymous reviewer for their valuable and constructive comments.

Topical Editor P. Drobinski thanks R. Eastman and another anonymous referee for their help in evaluating this paper.

\section{References}

Che, H., Zhang, X., Li, Y., Zhou, Z., and Qu, J.: Horizontal visibility trends in China 1981-2005, Geophys. Res. Lett., 34, L24706, doi:10.1029/2007GL031450, 2007.

Dai, A., Karl, T., Sun, B., and Trenberth, K.: Recent in cloudiness over the United States: A tale of monitoring inadequacies, B. Am. Meteorol. Soc., 87, 597-606, 2006.

Ding, Y., Wang, Z., and Sun, Y.: Inter-decadal variation of the summer precipitation in East China and its association with decreasing Asian summer monsoon. Part I: observed evidences, Int. J. Climat., 28, 1139-1161, 2008.

Huang, R., Gu, L., Chen, J., and Wang, G.: Recent progresses in studies of the temporal-spatial variations of the east Asian monsoon system and their impacts on climate anomalies in China, Chinese J. Atmos. Sci., 4, 691-719, 2008.

Henderson-Sellers, A.: Cloud changes in a warmer Europe, Clim. Change, 8, 25-52, 1986.

Jones, P. and Henderson-Sellers, A.: Historical records of cloudiness and sunshine in Australia, J. Climate, 5, 260-267, 1992.

Kaiser, D.: Decreasing cloudiness over China: An updated analysis examining additional variables, Geophys. Res. Lett., 27, 2193 2196, 2000 .

Koren, I., Martins, J., Remer, L., and Afargan, H.: Smoke invigoration versus inhibition of clouds over the Amazon, Science, 321, 946-949, 2008.

Li, Z., Chen, H., Cribb, M., Dickerson, R., Holben, B., Li, C., Lu, D., Luo, Y., Maring, H., Shi, G., Tsay, S., Wang, P., Wang, Y., Xia, X., Zheng, Y., Yuan, T., and Zhao, F.: Preface to special section on East Asian Studies of Tropospheric Aerosols: An International Regional Experiment (EAST-AIRE), J. Geophys. Res., 112, D22S00, doi:10.1029/2007JD008853, 2007.

Liang, F. and Xia, X. A.: Long-term trends in solar radiation and the associated climatic factors over China for 1961-2000, Ann. Geophys., 23, 2425-2432, doi:10.5194/angeo-23-2425-2005, 2005.
Luo, Y., Lu, D., Zhou, X., Li, W., and He, Q.: Characteristics of the spatial distribution and yearly variation of aerosol optical depth over China in last 30 years, J. Geophys. Res., 106, 14501-14513, 2001.

Milewska, E.: Baseline cloudiness trends in Canada 1953-2002. Atmos. Ocean, 42, 267-280, 2004.

Norris, J.: Has Northern Indian Ocean cloud cover changed due to increasing anthropogenic aerosol, Geophy. Res. Lett., 28, 32713274, 2001.

Qian, Y., Kaiser, D., Leung, R., and Xu, M.: More frequent cloud-free sky and less surface solar radiation in China from 1955 to 2000, Geophys. Res. Lett., 33, L01812, doi:10.1029/2005GL024586, 2006.

Qiu, J. and Yang, L.: Variation characteristics of atmospheric aerosol optical depths and visibility in North China during 19801994, Atmos. Environ., 34, 603-609, 2000.

Sun, B. and Groisman, P: Cloudiness variations over the former Soviet Union. Int. J. Climatol., 20, 1097-1111, 2000.

Sun, B. and Groisman, P.: Variations in low cloud cover over the United States during the second half of the twentieth century, J. Climate, 17, 1883-1888, 2004.

Wang, H.: The weakening of the Asian monsoon circulation after the end of 1970's, Advan. Atmos. Sci., 3, 376-386, 2001.

Wang, X.: Accounting for autocorrelation in detecting mean shifts in climate data series using the penalized maximal $\mathrm{t}$ or F test, J. Appl. Meteorol. Climatol., 47, 2423-2444, doi:10.1175/2008JAMC1741.1, 2008a.

Wang, X.: Penalized maximal $\mathrm{F}$ test for detecting undocumented mean shift without trend change, J. Atmos. Oceanic Technol., 25, 368-384, doi:10.1175/2007JTECHA982.1, 2008 b.

Warren, S., Eastman, R., and Hahn, C.: A survey of changes in cloud cover and cloud types over land from surface observations, 1971-96, J. Climate, 20, 717-730, doi:10.1175/JCLI4031.1, 2007.

Wild, M.: Global dimming and brightening: a review, J. Geophys. Res., 114, D00D16, doi:10.1029/2008JD011470, 2009.

Wild, M.: Enlightening global dimming and brightening, B. Am. Meterol. Soc., 93, 27-37, 2012.

Xia, X.: Spatiotemporal changes in sunshine duration and cloud amount as well as their relationship in China during 1954-2005, J. Geophys. Res., 115, D00K06, doi:10.1029/2009JD012879, 2010a.

Xia, X.: A closer looking at dimming and brightening in China during 1961-2005, Ann. Geophys., 28, 1121-1132, doi:10.5194/angeo-28-1121-2010, 2010b. 